\title{
Multiphase tectonic movements, cap formations and evolution of the Majiang paleo-reservoir
}

\author{
Tang Liangjie ${ }^{1 *}$ and Cui Min²
}

\author{
${ }^{1}$ State Key Laboratory of Petroleum Resources and Prospecting, China University of Petroleum, Beijing 102249, China \\ ${ }^{2}$ CNOOC Research Institute, Beijing 100027, China \\ (C) China University of Petroleum (Beijing) and Springer-Verlag Berlin Heidelberg 2011
}

\begin{abstract}
The Majiang paleo-reservoir is a typical destroyed hydrocarbon reservoir, buried in carbonate strata of China's southern marine-facies. Field geological explorations, interpretations of seismic profiles and balanced cross-section restorations around this paleo-reservoir reveal that its formation and evolution have been restricted by multiphase tectonic movements of different intensities. A regional tectonic mechanism and model have been suggested for the formation and evolution of the Majiang paleoreservoir. Geological field exploration has been carried out along three typical Silurian cross-sections and rock samples were tested in combination with water-rock interaction. Based on the result of cap tests, the planar distribution, the residual thickness, the erosion thickness and the preservation conditions, the Silurian mudstone cap is discussed around the Majiang paleo-reservoir. Combining the hydrodynamic conditions of its formation and evolution and its tectonic movements, we determined the fact that the thicker the cap is, the more resistant it is to hydrodynamic destruction. The multi-phase formation and destructive geological model of the paleo-reservoir is established through an overall analysis of multiphase tectonic evolutions, cap developments, hydrodynamic conditions and solid mineral metallogenic ages measured by $\mathrm{Rb}-\mathrm{Sr}, \mathrm{Pb}$ and $\mathrm{Sm}-\mathrm{Nd}$ isotope techniques.
\end{abstract}

Key words: Multiphase tectonic evolution, key tectonic changes, cap evolution, hydrocarbon preservation, Majiang paleo-reservoir

\section{Introduction}

Marine carbonate rock systems are quite ancient and distributed deep in the multi-phase superimposed basins of China. They developed in multiple source rocks. During the long geological history over hundreds of millions of years, hydrocarbon generation and expulsion processes occurred several times, which created conditions for multi-phase accumulation in carbonate rock systems (Jin, 2005; Jin and Cai, 2006). At different stages of geological history, marine carbonate rock systems formed faults, folds and unconformities on varied geodynamic backgrounds. Complex deformations include the characteristics of geometry and kinematics, the superposed reformation and the different kinematic mechanisms of deformation styles. These events, which can be analyzed in accordance with the scale of outcrops and the scale measured with geophysical oil prospecting, changed the structure of early marine carbonate rock systems. They restrict the evolution of basins, sedimentary systems and the trapping conditions of oil and

*Corresponding author. email: tanglj@cup.edu.cn

Received March 22, 2010 gas accumulation at the later stage. One of the key scientific issues (Jin et al, 2006; Tang et al, 2008) is the hydrocarbon accumulation and preservation process controlled by the multi-phase tectonic activity of superimposed basins, and by the constraint of the key tectonic characteristics on the preservation conditions of oil and gas reservoirs in marine carbonate rocks.

Previous geologists have done a great deal of work on marine carbonate rock systems in China, and achieved many important results (Liu, 2001; Qiu, 2000; Sun, 1991; Zhai and Wang, 2000). They investigated the structural movement of deep-buried marine strata and its effects on the evolution of hydrocarbons to the two poles (Zhai and Wang, 2000). The tectonic stress of marine systems plays an important role in the process of oil and gas reservoir formation and distribution (Qiu, 2000); and they presented tectonic movements that wrought different effects on the destruction as well as the preservation of oil and gas reservoir areas (Guo et al, 2003; $\mathrm{Li}, 1997)$. The methodology to distinguish an oil and gas preservation process in areas with multiphase tectonic movement is summarized (He et al, 2004). There are three aspects of preservation conditions: the demonstrated different mechanisms of multi-phase tectonic activities on destruction and preservation of oil and gas reservoirs, characteristics 
and evolutions of oil and gas reservoir caps, and interactive mechanisms between fluid and cap rock.

The Majiang paleo-reservoir is a typical example of reservoir formation and destruction in a marine carbonate system of south China. The recent study result shows that the paleo-reservoir is a trap type generated due to the combination of tectonic structures and lithology (Guo et al, 2003; Xiang et al, 2008). The main source rocks are black mudstone and carbonaceous mudstone of the lower Cambrian series. The reservoir stratum contains sandstone of the third Member in the Wengxiang Group of lower middle Silurian series and the fractured porous reservoir in the Honghuayuan Formation of lower Ordovician series. The oil generation peak period spans from the early Silurian to the early mid-Devonian stage. The major reservoir was filled in the late Caledonian stage, with a crude oil reserve of over 1.5 billion tons (Zhou, 2006). This paper is intended to discuss the geologic factors for oil and gas preservation, with analyses of multi-phase tectonic evolution, cap characteristics and evolution of the paleoreservoir.

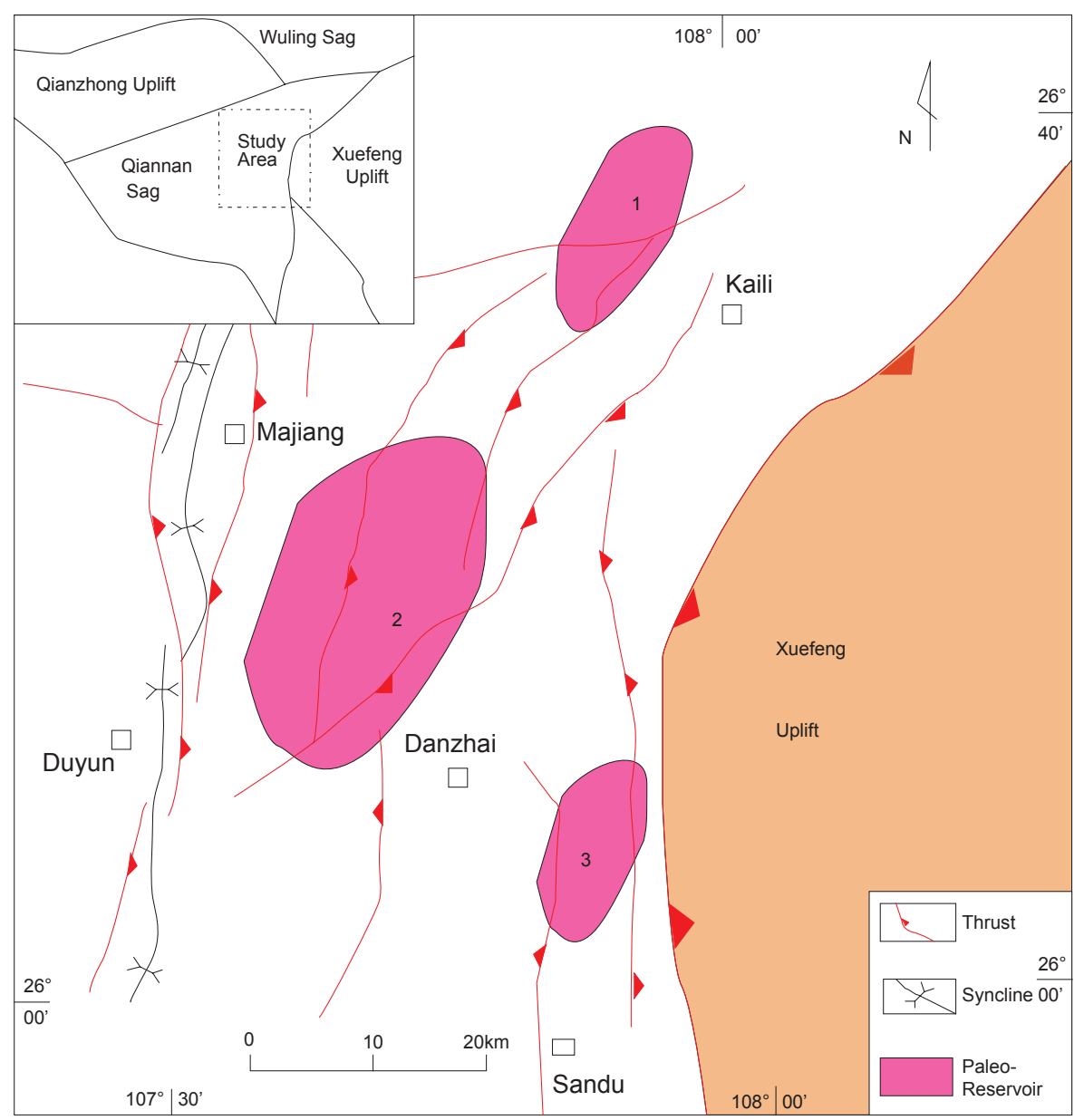

Fig. 1 Distribution of the paleo-reservoirs in the South Guizhou Depression

1. Kaili-Huzhuang anticline-type residual oil and gas reservoir $\left(\mathrm{O}_{1}-\mathrm{S}_{1}\right) ; 2$. Majiang anticline-type paleo-reservoir $\left(\mathrm{O}_{1}-\mathrm{S}_{1}\right) ; 3$. Danzhai anticline-type lithologic paleo-reservoir $\left(\in_{1}\right)$

\section{Multi-phase structural movements}

There were several structural movements of different intensities, in which different structural styles have been shown during the evolution of the Majiang paleo-reservoir which rests in the transitional zone between the Qiannan Depression and the Xuefeng Uplift and is considered to be one of the largest paleo-reservoirs in marine residual units of south China (see Fig.1). The geological exploration, seismic cross-sectional interpretation and analysis of joints indicate that the formation and evolution of the paleoreservoir is restricted by multi-phase structural movements of different intensities (Dong et al, 2008; Tang et al, 2008). In these structural movements, the key tectonic transitional stage includes the Duyun, Guangxi, Indosinian, Yanshan and Himalayan movements. The Duyun movement (late Ordovician) formed a series of axial wide and gentle fold structures in the NNE direction in the Majiang region; and the Guangxi movement (late Silurian), the Dongwu movement (late Permian), and the Indosinian movement further accentuated these folds. The late Yanshan movement (Cretaceous) superposed them; and the superposition arranged those large-scale wide gentle folds into a series of folded structures in an axial NE direction and of an echelon shape 
(Tang et al, 2008). The seismic cross-sectional interpretation and balanced cross-sectional restoration demonstrate that the main tectonic activities of the Duyun and Guangxi movements occurred chiefly in the form of uplift and vertical erosion. The tectonic activities at the Indosinian stage were weak. The Yanshan and Himalayan movements produced the strongest horizontal compressional force. Thirty samples of sandstones and carbonate rocks of both the Devonian and the Banxi Group were collected from the surrounding area of the paleo-reservoir. Five hundred and thirty-six transmission electron microscope (TEM) images were taken, and over 5,500 dislocation lines were delineated (see Fig. 2). The dislocation density method shows that the paleo-stress values of the Duyun and Guangxi movements are small, only between 20-30 MPa. The main tectonic activities of the Yanshan and Himalayan movements mainly exhibited strong horizontal compression, faults, folds, uplifts and erosions, with relatively large paleo-stress values between 50-70 $\mathrm{MPa}$. For the acoustic emission of the Permian and Triassic, their paleo-stress value is the same as their acoustic frequency,
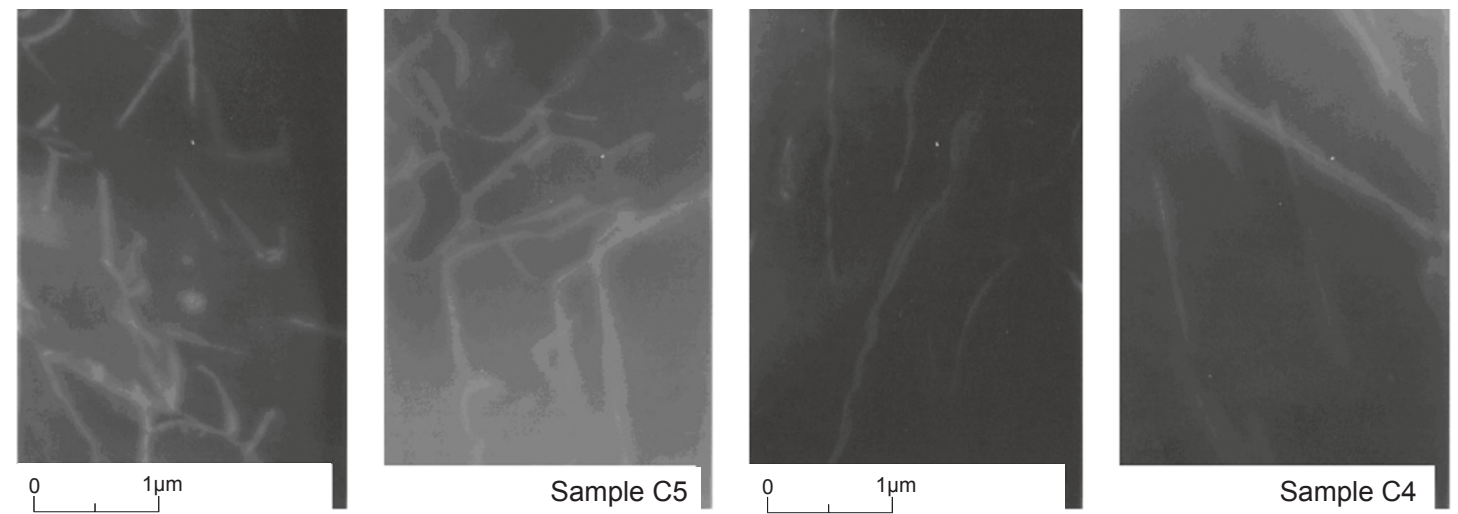

Fig. 2 TEM images of dislocation densities from the sandstone around the Majiang paleo-reservoir

which indicates that there may not have been large-scaled tectonic movements at the Indosinian stage. The findings are consistent with those from the analysis of balanced crosssections (Cui et al, 2009).

\section{Cap formations}

Field exploration was conducted along typical Silurian cross-sections in the Qiannan Depression. Samples of mudstone caps were tested and analyzed in combination with water-rock dissolubility tests. The investigation was made to predict the planar distribution, residual thickness, erosion and preservation conditions of the Silurian mudstone cap of the Majiang paleo-reservoir. The cap type and preservation condition of the paleo-reservoir were confirmed. The Lvyinqiao cross-sectional profile illustrates that if the confining pressure of the mudstone cap is $20 \mathrm{MPa}$ and the average saturated kerosene breakthrough pressure is 6.2 $\mathrm{MPa}$, then the average porosity is $3.0 \%$, and the average permeability is $0.0303 \mathrm{mD}$ (see Fig. 3). Fifteen samples were collected from the Bagu Silurian cross-section, with
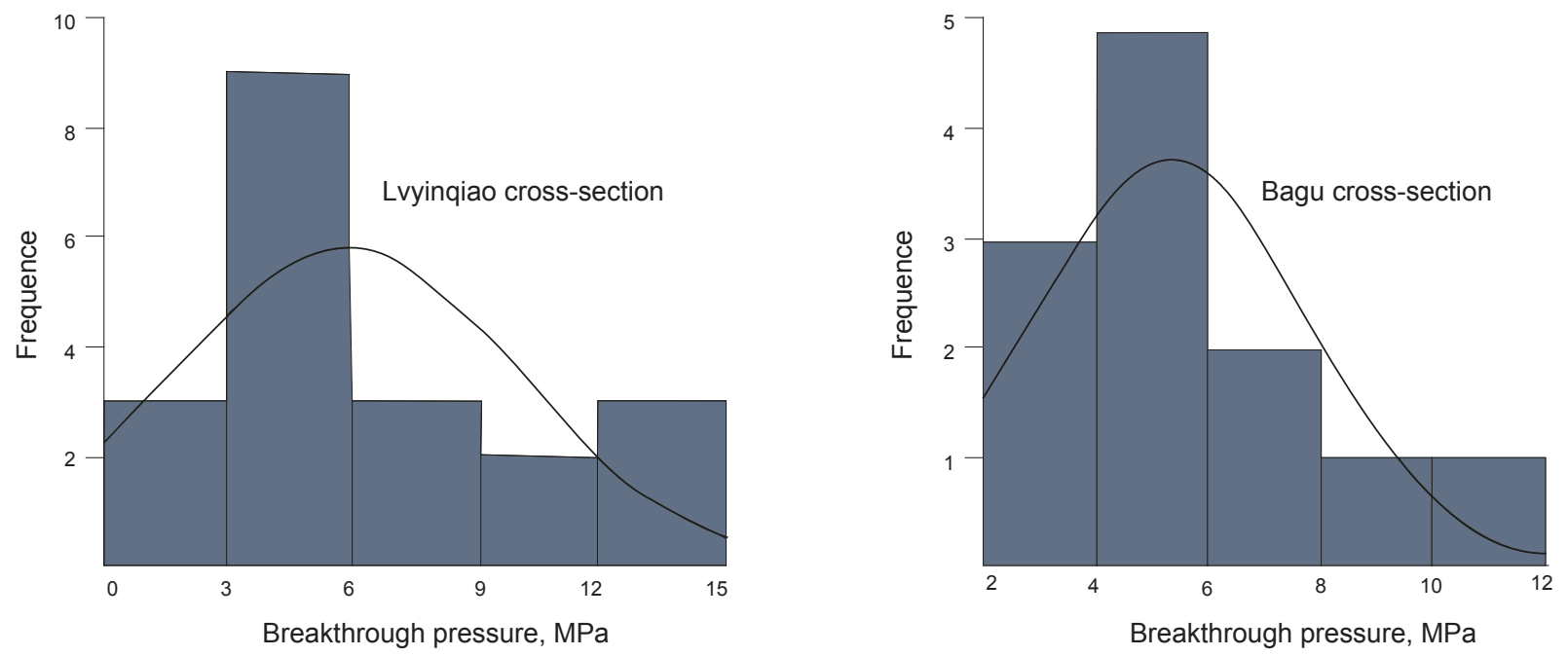

Fig. 3 Frequency distribution chart of the cross-sectional breakthrough pressure along the typical 
Table 1 Evaluation criterion for gas cap rock (Deng et al, 2000)

\begin{tabular}{|c|c|c|c|c|c|c|}
\hline $\begin{array}{c}\text { Permeability } \\
\mathrm{mD}\end{array}$ & $\begin{array}{c}\text { Porosity } \\
\%\end{array}$ & $\begin{array}{c}\text { Breakthrough } \\
\text { Pressure } \\
\mathrm{MPa}\end{array}$ & $\begin{array}{c}\text { Chlorite } \\
\%\end{array}$ & Fracture & Main Lithology & Cap Classification \\
\hline $10^{-9}$ & 1.5 & 14.9 & 5 & None & Saline rock, Mudstone, Bauxite rock & 1 (best) \\
\hline $10^{-8}$ & $>2$ & 10.5 & 8 & None & Mudstone, Carbonaceous mudstone, Limestone & $2(\operatorname{good}+)$ \\
\hline $10^{-7}$ & $>5$ & 6.0 & 15 & None & Muddy siltstone, silty mudstone & 3 (good-) \\
\hline $10^{-6}$ & $>7$ & 2.6 & 20 & Tiny & Muddy siltstone, silty mudstone & 4 (general) \\
\hline $10^{-5}$ & $>7$ & 1.0 & $<20$ & Tiny & Muddy fine-grained sandstone, Muddy siltstone & 5 (bad) \\
\hline $10^{-4}$ & 10 & 0.4 & $<20$ & Tiny & Muddy fine-grained sandstone, Siltstone & Special conditions \\
\hline
\end{tabular}

the average saturated kerosene breakthrough pressure being 5.3MPa, and the average porosity and permeability being $4.1 \%$ and $0.0303 \mathrm{mD}$ respectively (see Fig. 3). The surface samples fall within Class 2 cap (good) (see Table 1).

According to the micro-features and the analyses of diagenesis, the Silurian is made up of dense massive sandy bedded mudstone and the illite is laminated in the Majiang paleo-reservoir. Inter-granular micro-pores are developed among clay minerals and detrital particles. Micro-pores are also developed between the clay mineral layers. The mudstone here assumes a compact structure in the Wengxiang Group, and the overall sealing property is good according to the diagenetic grade. The illite crystallinity is $0.65-0.68$, and the mixed-layer ratio is 15 , located in the lower $\mathrm{B}$ part at the late diagenetic stage (Tang et al, 2008). Within a certain burial spectrum, the greater the depth is, the stronger the compaction diagenesis is, therefore causing the clay mineral particles to be more compacted. The mudstone porosity is lower and the pore radius is reduced, jointly leading to the weakened permeability, which in turn increased the displacement pressure and improved the sealing capacity of the capilliaries. For the rocks, when compaction increases, the plasticity is reduced, and the brittleness is increased; micro-cracks would easily occur due to the transformation of late structural movements, hence part of the mudstone would have a lower sealing capacity. The dissolution rate of mudstone is faster in the surface fresh water than in salty water, which indicates that the dissolution rate of buried mudstone is evidently lower than that on the surface. The currently outcropped mudstone has a good sealing capacity when buried deep.

\section{Construction and destruction of the Majiang paleo-reservoir}

Corresponding to multi-phase tectonic evolution, the Caledonian and the Yanshan-Himalayan stages are the main stages of meteoric water infiltration in the Qiannan Depression, and the destruction of the Majiang paleo-reservoir from late tectonic activities is strong. The evolutional characteristics of the paleo-fluid dynamic field demonstrates that the deeper the cap is buried, the weaker the hydrodynamic damage; and the shallower the cap is buried, the more severe the hydrodynamic damage. The Caledonian-Hercynian stage is one at which oil was mostly generated (Fig. 4); the destruction in the
Hercynian movement was relatively weak. During the Indosinian stage, the oil reservoir is decomposed into a gas reservoir at a high temperature (Fig. 4). At the OrdovicianSilurian stage, the source rock began to generate oil. This is an important accumulation stage with limited destruction(Fig. 4). The Yanshan-Himalayan movement destroyed the oil reservoir with strong uplift and erosion (Fig. 4). The results from hydro-geological cycles of the Qiannan Depression also correspond respectively to the regional key tectonic transitions: the Duyun, Guangxi, Indosinian, Yanshan and Himalayan movements (Lou et al, 2008). During the paleouplift meteoric water strongly infiltrated and damaged the paleo-reservoirs during multi-phase oil and gas accumulation. The preservation conditions appeared better towards the centre of the depression. In the Majiang-Kaili area of the Qiannan region, the outcrop there commonly records episodic fluid activities at the fifth stage of the second episode. Based on the stratigraphic age of authigenic minerals, and the structural evolution of the Qiannan Depression, the authigenic minerals in the fractures of the paleo-reservoir are mainly formed at the Indosinian and Yanshan-Himalayan stages, corresponding to the secondary reservoir-forming stage and final destruction of the paleo-reservoir.

Analyses are made of multi-phase tectonic evolution, cap development, hydrodynamic conditions as well as the solid mineral metallogenic epochs for the ancient reservoir. Together with $\mathrm{Rb}-\mathrm{Sr}, \mathrm{Pb}$ and $\mathrm{Sr}-\mathrm{Sm}$ isotopes measurements, a two-phase accumulation (Caledonian Stage and Indosinian Stage) and destruction model is established for the reservoir: The dominant accumulation stage includes the Caledonian and Indosinian stages; the main destructive phases are the late Caledonian and Yanshan-Himalayan stages. The Duyun and Guangxi movements were mainly uplifting and erosional activities, restricting the burial depth, thickness and fracture development of the mudstone cap of the Silurian System and controlling the vertical preservation of the reservoir cap.

The Yanshan and Himalayan movements destroyed the Majiang paleo-reservoir by tectonic forces of faulting, folding, nappe thrusting and uplifting erosion. The Xuefeng Uplift was thrusting during the late Yanshan movement. Because of the presence of multiple detachment and the different thrusting, high-angle thrust faults broke through and were well developed in the periphery of the Xuefeng Uplift around the paleo-reservoir. Based on the slope of the burial history 


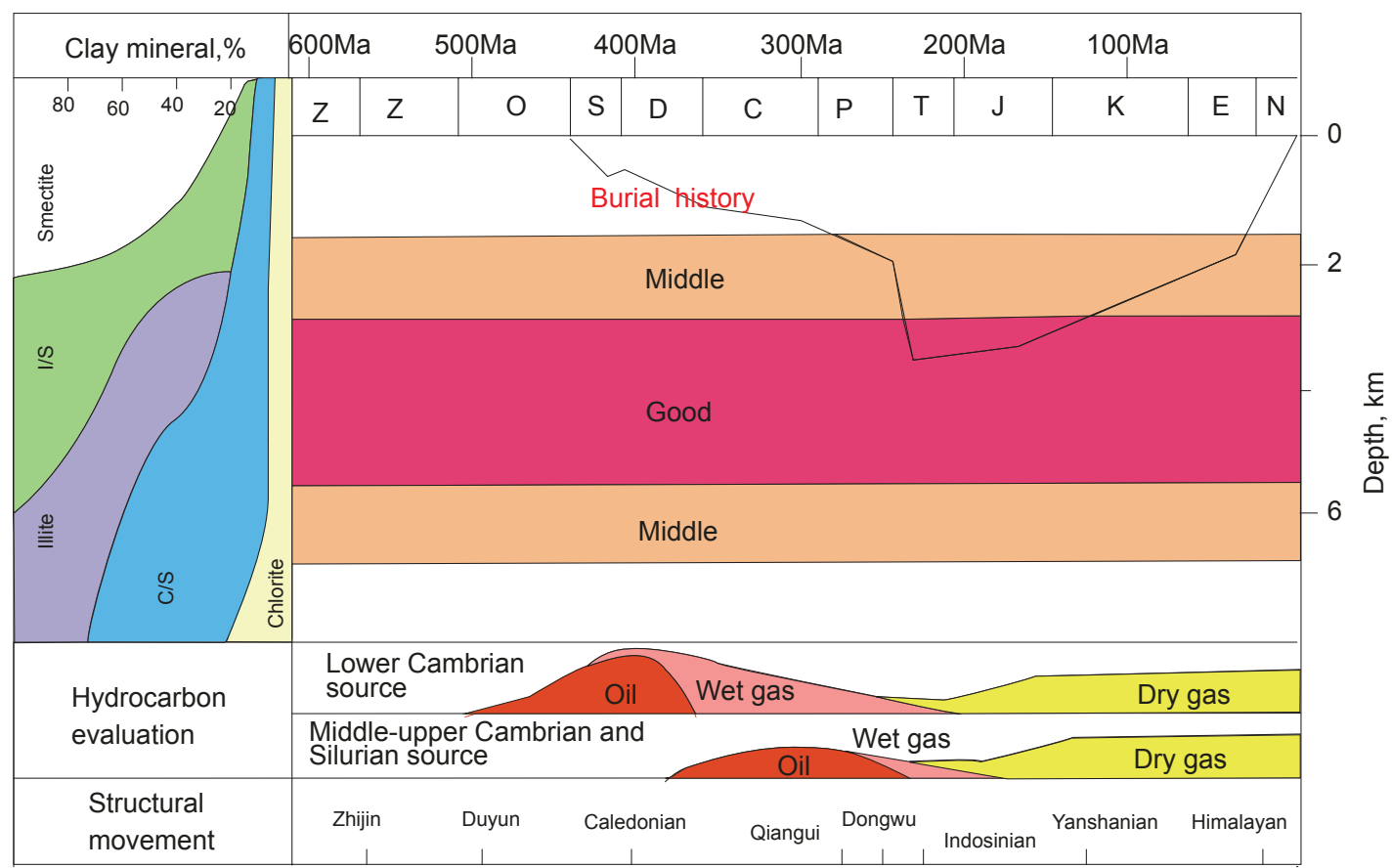

Fig. 4 Multi-phase structural movement, cap development, reservoir-forming, destruction and evolution of Majiang paleo-reservoir

line in Fig. 4, two stages were discovered. The first stage is pre-Indosinian, when the main structural style reveals folding and vertical movement. The second stage is post-Indosinian, when the main structural style presents breakthrough faulting and horizontal movement; the preservation becoming poor slowly. In the Himalayan movement, the reservoir was uplifted quickly and broke up finally.

Based on the statistical correlation between the Ro value of Barker vitrinite reflectance and the maximum temperature

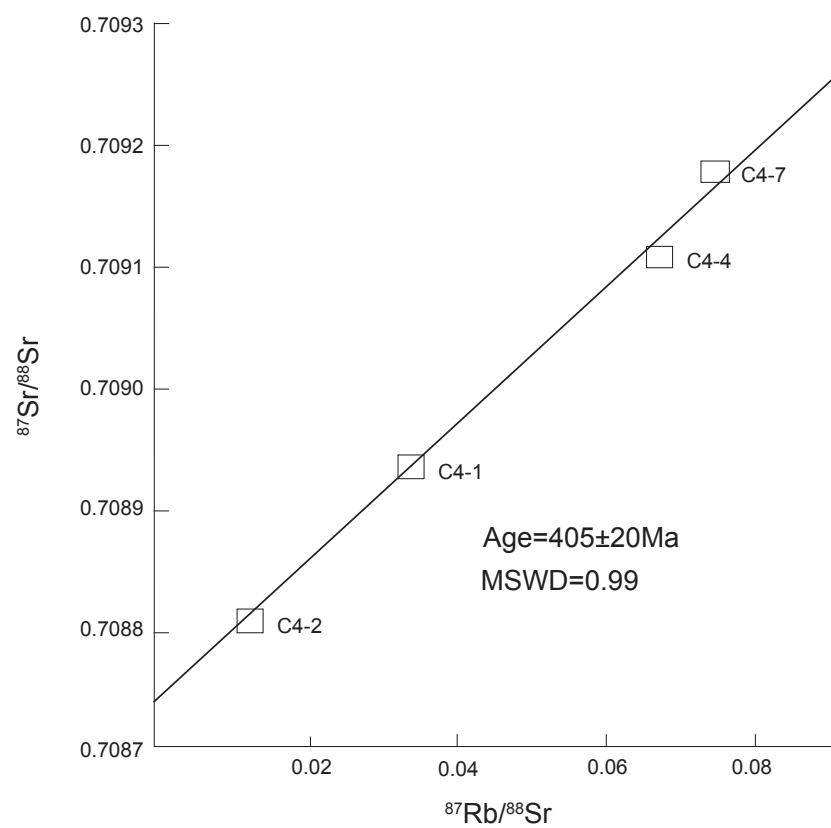

Fig. $5 \mathrm{Rb} / \mathrm{Sr}$ isotope age (partial) of Maijiang paleo-reservoir
$\mathrm{T}$ it experienced, Zhou (2006) determined that the maximum temperature of asphalt in the Kaili Reservoir falls between $122{ }^{\circ} \mathrm{C}$, and $148{ }^{\circ} \mathrm{C}$, that the maximum depth is up to approximately $4000 \mathrm{~m}$ and that the age of the forming of such asphalt is the late Triassic, based on the geothermal gradient $\left(3.2{ }^{\circ} \mathrm{C} / 100 \mathrm{~m}\right)$. By measuring the mean temperature of fissure filling, together with the geothermal gradient and burial history, he concluded that the asphalt finally decomposed into methane-based dry gas and residual asphalt at the Yanshan stage.

Using $\mathrm{U}-\mathrm{Pb}, \mathrm{Pb}-\mathrm{Pb}, \mathrm{Rb}-\mathrm{Sr}$ and $\mathrm{Sm}-\mathrm{Nd}$ isotopic systems in the crude oil, bitumen and kerogen, the age of hydrocarbon generation, migration and accumulation can be determined, while $\mathrm{U}, \mathrm{Pb}, \mathrm{Rb}, \mathrm{Sr}$ and other metals exist as organic complexes, chemical adsorbents and debris mixed with other materials in the asphalt, of which three the organic complex is the chief target for the geochronology of hydrocarbon accumulation. The asphalt samples are collected near Pojiao Village, Bagu, Duyun city. The collected asphalt, which is developed mainly in the joints and cracks of dolomite that lies beneath the thick Honghuayuan Formation in the lower Ordovician, is a typical epigenetic reservoir bitumen.

There were seven kinds of asphalt used for $\mathrm{Rb}-\mathrm{Sr}$ and $\mathrm{Pb}$ $\mathrm{Pb}$ dating. The separating, selecting, enriching and testing of the bitumen samples are done in the Beijing Geological Research Institute under the Ministry of Nuclear Industry, and the equipment involved is a British GV-new high-precision solid thermal ionization mass spectrometer, IsoProbe-T. The ratio and content of $\mathrm{Sr}$ isotope are measured using a dynamic multi-receiver, the ratio and content of $\mathrm{Rb}$ and $\mathrm{Pb}$ isotopes were measured with a single receiver. How the equipment was working was monitored by the International Standards, 
the mean value of NBS981 lead standards ${ }^{206} \mathrm{~Pb} /{ }^{204} \mathrm{~Pb}=$ $16.911 \pm 0.007,{ }^{207} \mathrm{~Pb} /{ }^{204} \mathrm{~Pb}=15.459 \pm 0.012$, and ${ }^{208} \mathrm{~Pb} /{ }^{204} \mathrm{~Pb}$ $=36.602 \pm 0.033$. SRM987 $\mathrm{Sr}$ standard average ${ }^{87} \mathrm{Sr} r{ }^{86} \mathrm{Sr}=$ $0.710283 \pm 0.002$. The blank $\mathrm{Pb}$ during the experimental process is $2 \times 10^{-10} \mathrm{~g}, \mathrm{Rb}$ is $5 \times 10^{-10} \mathrm{~g}$, and $\mathrm{Sr}$ is $5 \times 10^{-10} \mathrm{~g}$. After an adjustment of the background and dilution, the data acquired are regressed by IsoPlot isochron, and the samples can be classified into two groups. The first group includes four samples C4-1, C4-2, C4-4 and C4-7, and their age is $405 \pm 20 \mathrm{Ma}$ (Fig. 5). The remaining three samples of the $\mathrm{Sr}$ content are similar, resulting in bigger errors in age (195 \pm $65 \mathrm{Ma})$. Although there are big errors in the three samples, it still can be confirmed that there are two age groups for the asphalt. The ratio of ${ }^{206} \mathrm{~Pb} /{ }^{204} \mathrm{~Pb}$ is 18.6 , but six of the seven samples show the $\mathrm{Pb}$ isotope positive anomaly (Table 2 ), indicating that there are some radioactive $\mathrm{Pb}$ and other radioactive elements that came at the later stage and mixed into the asphalt during their formation, resulting in $\mathrm{ab}-\mathrm{Pb}$ age datum that cannot constitute a valid isochron.

In addition, the metallogenic epoch of mercury, antimony and gold formed as minerals was from the early Silurian till the early Triassic stages in the Danzhai area. The case is the same with Fenghuang-Xinhuang mercury belt ( $\mathrm{Hu}$ et al, 2007). In the Yanshan tectonic movement, magmatic activity and infiltration of heated meteoric water activated and migrated the deposited ore-forming materials, leading to the forming of ore veins in the Yanshan fault structure, or oxidization and concentration of the rock or ore close to the ground surface. While the tectonic movement destroyed the oil and gas reservoir, it changed the oxidation and reduction conditions of metal-rich hot brine at the crude oil-water interface, causing minerals to deposit from ore-bearing hot brine. The later strong structural movement transformed these metal deposits. The $\mathrm{Sm}-\mathrm{Nd}$ isotopic age data cannot constitute a valid isochron (Table 3 ) but show the presence of introduced radioactive $\mathrm{Nd}$ isotopes. In combination with the structural deformation, vitrinite reflectance and other radioactive elements, it is believed that the two-phase oreforming and destruction of the paleo-reservoir is related to the formation of uranium ore and mercury ore.

Table $2 \mathrm{~Pb}$ isotope characteristics of Majiang paleo-reservoir

\begin{tabular}{cccccc}
\hline${ }^{208} \mathrm{~Pb} /{ }^{204} \mathrm{~Pb}$ & Std err & ${ }^{207} \mathrm{~Pb} /{ }^{204} \mathrm{~Pb}$ & Std err & ${ }^{206} \mathrm{~Pb} /{ }^{204} \mathrm{~Pb}$ & Std err \\
\hline 38.241 & 0.007 & 15.666 & 0.003 & 18.752 & 0.003 \\
38.146 & 0.009 & 15.598 & 0.004 & 18.393 & 0.004 \\
37.991 & 0.029 & 15.663 & 0.012 & 18.955 & 0.015 \\
38.309 & 0.005 & 15.705 & 0.002 & 19.022 & 0.003 \\
38.155 & 0.005 & 15.626 & 0.002 & 18.645 & 0.002 \\
38.368 & 0.006 & 15.696 & 0.003 & 18.881 & 0.003 \\
38.316 & 0.005 & 15.828 & 0.002 & 20.696 & 0.003 \\
\hline
\end{tabular}

Table $3 \mathrm{Sm}-\mathrm{Nd}$ isotope characteristics of Maijiang paleo-reservoir

\begin{tabular}{ccccc}
\hline $\begin{array}{c}\mathrm{Sm} \\
\mu \mathrm{g} / \mathrm{g}\end{array}$ & $\begin{array}{c}\mathrm{Nd} \\
\mu \mathrm{g} / \mathrm{g}\end{array}$ & ${ }^{147} \mathrm{Sm} /{ }^{144} \mathrm{Nd}$ & ${ }^{143} \mathrm{Nd} /{ }^{144} \mathrm{Nd}$ & Std err \\
\hline 0.103 & 0.692 & 0.0896 & 0.511826 & 0.000006 \\
0.016 & 0.116 & 0.0830 & 0.511700 & 0.000013 \\
0.028 & 0.182 & 0.0945 & 0.511761 & 0.000013 \\
0.078 & 0.517 & 0.0917 & 0.511760 & 0.000010 \\
0.011 & 0.070 & 0.0911 & 0.511630 & 0.000012 \\
0.033 & 0.231 & 0.0861 & 0.511775 & 0.000008 \\
0.227 & 1.38 & 0.0994 & 0.511873 & 0.000010 \\
\hline
\end{tabular}

\section{Conclusions}

The formation and evolution of the Majiang paleoreservoir have experienced some key tectonic transition stages, including the Duyun, Guangxi, Indosinian, Yanshan and Himalayan movements, while the main accumulation phase was at the Caledonian and Indosinian stages and the main destructive phase was at the late Caledonian and Yanshan-Himalayan stages. The Duyun and Guangxi movements mainly resulted in uplift and erosion, restricting the burial depth, thickness and fracture development of the mudstone cap of the Silurian System and controlling the vertical preservation of the paleo-reservoir cap. The Yanshan and Himalayan movements destroyed the paleo-reservoir with tectonic forces such as faulting, folding, thrust nappes and uplifting erosion. Geological analyses, sample tests, dissolution tests and hydrodynamic analyses prove that the sealing capability of the Silurian cap is good at a certain depth of burial. An analysis of what has happened in the paleoreservoir plays an important role in oil and gas exploration in south China. There are two stages of hydrocarbon accumulation, namely Caledonian and Indosinian stages. Two tectonic movements, the Yanshan and Himalayan movements, are the chief contributors to destroying the reservoir. Where the conditions are good for preservation, such as control of the reservoir by the source rocks, there is an exploration target when the structural movement is weak and the cap is deep enough to make a key exploration area. The overthrust of the Xuefeng uplift and the centre of the Qianzhong uplift are ideal areas for petroleum preservation in south China.

\section{Acknowledgements}

This research received financial support from the National Natural Science Foundation of China (Grant Nos. 40972090, 40672143 and 40172076), the National Major Fundamental Research and Development Project (Grant Nos. 2005CB422107 and G1999043305), and the National Science and Technology Project (Grant Nos. 2008ZX05005-002-04- 
02). The authors sincerely thank Ma Zongjin, Jia Chengzao, Jin Zhijun, Liu Hefu and others for helpful discussions and suggestions for improving the manuscript.

\section{References}

Cui M, Tang L J, Wang P H, et al. Characteristics of the paleo-stress at the southwest margin of the Xuefeng Uplift and its significance to petroleum geology. Journal of Geomechanics. 2009. 15(3): 289-295 (in Chinese)

Deng Z Y, Wang S C, Jiang Z L, et al. Breaking pressure of gas cap rocks. Oil \& Gas Geology. 2000. 21(2): 136-138 (in Chinese)

Dong L, Tang L J, Lu X M, et al. Joint development features and their functions as indicators for stress field transformation in the Majiang area. Oil \& Gas Geology. 2008. 29(6): 740-747 (in Chinese)

Guo T L, Lou Z H, and M Y S. Several problems on oil and gas preservation and their commercial prospecting in marine sequences of South China. Experimental Petroleum Geology. 2003. 25(1): 3-9 (in Chinese)

He D F, Ma Y S, and Yang M H. Concept and appraisal principles of hydrocarbon preservation unit. Oil \& Gas Geology. 2004. 25(2): 2-8 (in Chinese)

Hu Y Z, Han R S, and Mao X X. Relationship between metal mineralization and accumulation of oil and gas in east Guizhou. Geology \&Prospecting 2007. 43(5): 51-56 (in Chinese)

Jin Z J. Particularity of petroleum exploration in marine carbonate strata in China's sedimentary basins. Earth Science Frontiers. 2005. 12(3): 15-22 (in Chinese)

Jin Z J, and Cai L G. Exploration prospects, problems and strategies of marine oil and gas in China. Oil \& Gas Geology. 2006. 27(6): 722730 (in Chinese)

Jin Z J, Long S X, Zhou Y, et al. A study of the distribution of saline deposits in south China. Oil \& Gas Geology. 2006. 27(5): 571-583 (in Chinese)

Li M C. Integrative study of preservation conditions of oil and gas pools. Acta Petrolei Sinica. 1997. 18(2): 41-48 (in Chinese)

Liu G D. Pre-Cenozoic marine residual basins. Progress In Geophysics. 2001. 16(2): 1-7

Lou Z H, Zhu R, Jin A M, et al. Relationship between groundwater and hydrocarbon accumulation-preservation in sedimentary basin. Acta Geologica Sinica. 2008. 83(8): 1188-1194 (in Chinese)

Qiu Z J. New Technology promotes the Discovery of the Tarim Natural Gas Province. Chinese Engineering Science. 2000. 9(2): 38-41 (in Chinese)

Sun Z C. On the relationship of the intraplate deformation and the secondary formation of oil/gas pools - general regularities of the oilgas formation in an marine environment of the Yangtze area. Experimental Petroleum Geology. 1991. 13(2): 107-142 (in Chinese)

Tang L J, Guo T L, Tian H Q et al. Poly-cycle tectonic evolution, differential deformation and hydrocarbon reservation in central Guizhou and adjacent region. Acta Geologica Sinica. 2008. 82(3): 298-307 (in Chinese)

Xiang C F, Tang L J, Jin Z J. et al. Outcrop sequence stratigraphy of the Majiang ancient oil reservoir and suggestions for the study of the sealing capability of the marine oil field that developed in south China. Acta Geologica Sinica. 2008.82(3):346-352 (in Chinese)

Zhai G M, and Wang $\mathrm{J} J$. The regularity of petroleum pool distribution in oil-bearing basins of China. Acta Petrolei Sinica. 2000. 21(1): 1-9 (in Chinese)

Zhou F. Hydrocarbon accumulation and petroleum formation at the northern margin of Jiangnan uplift. Wu han: China University of Geology[Thesis]. 2006 (in Chinese)

(Edited by Yang Lei) 